Research, Society and Development, v. 9, n. 10, e7279108754, 2020

(CC BY 4.0) | ISSN 2525-3409 | DOI: http://dx.doi.org/10.33448/rsd-v9i10.8754

\title{
A pedagogia Waldorf e a Base Nacional Comum Curricular na formação da criança
}

Waldorf pedagogy and the Common National Curriculum Base in the education of children

La pedagogía Waldorf y la Base Común de Currículos Nacionales en la educación de los niños

Recebido: 24/09/2020 | Revisado: 25/10/2020 | Aceito: 14/10/2020 | Publicado: 16/10/2020

Gabriela Luz Saraiva

ORCID: https://orcid.org/0000-0001-6957-799X

Universidade Franciscana, Brasil

E-mail: gabrielasaraiva163@gmail.com

Marcele Pereira da Rosa Zucolotto

ORCID: https://orcid.org/0000-0002-6856-8626

Universidade Franciscana, Brasil

E-mail: marcele.rosa@ufn.edu.br

\section{Resumo}

Este artigo tem como objetivo principal fazer uma apresentação da Pedagogia Waldorf relacionando-a com as competências gerais para a educação básica apontadas pela Base Nacional Comum Curricular (BNCC). Para tanto, realizou-se um estudo de cunho teórico buscando compreender como esta pedagogia coloca em prática o desenvolvimento das competências estabelecidas na Base Nacional Comum Curricular e se a mesma consegue atender ao desenvolvimento do aluno considerando as competências estabelecidas pela Base. Como resultados, percebeu-se que a pedagogia Waldorf pode ser entendida como uma alternativa de concretização dos preceitos da BNCC, tendo em vista que ambas se esforçam por fomentar um ser humano ético, livre, crítico, autônomo. Por fim, espera-se que este estudo possa contribuir para o campo educacional, tendo em vista que o foco deste, a pedagogia Waldorf, apresentou-se não apenas como uma possibilidade de consolidação das normativas da BNCC, mas principalmente como possibilidade de que a práticas pedagógicas possam contribuir para a formação de seres humanos integrais aptos a atuarem eticamente em nossa sociedade.

Palavras-chave: Pedagogia Waldorf; Base Nacional Comum Curricular; Competências. 


\section{Abstract}

This article has as main objective to make a presentation of the Waldorf Pedagogy relating it to the general competences for basic education pointed out by the National Common Curricular Base (BNCC). To this end, a theoretical study was carried out in order to understand how this pedagogy puts into practice the development of the competencies established in the National Common Curricular Base and whether it can meet the student's development considering the competencies established by the Base. As a result, it was realized that the Waldorf pedagogy can be understood as an alternative to implement the precepts of the BNCC, considering that both strive to foster an ethical, free, critical, autonomous human being. Finally, it is expected that this study can contribute to the educational field, considering that its focus, Waldorf pedagogy, presented itself not only as a possibility of consolidating the BNCC rules, but mainly as a possibility that the pedagogical practices can contribute to the formation of integral human beings able to act ethically in our society.

Keywords: Waldorf pedagogy; Common National Curricular Base; Skills.

\section{Resumen}

Este artículo tiene como objetivo principal hacer una presentación de la Pedagogía Waldorf relacionándola con las competencias generales para la educación básica señaladas por la Base Curricular Común Nacional (BNCC). Para ello, se realizó un estudio teórico con el fin de comprender cómo esta pedagogía pone en práctica el desarrollo de las competencias establecidas en la Base Curricular Común Nacional y si puede atender el desarrollo del estudiante considerando las competencias establecidas por la Base. Como resultado, se comprendió que la pedagogía Waldorf puede entenderse como una alternativa para implementar los preceptos del BNCC, considerando que ambos se esfuerzan por fomentar un ser humano ético, libre, crítico y autónomo. Finalmente, se espera que este estudio pueda contribuir al campo educativo, considerando que su enfoque, la pedagogía Waldorf, se presentó no solo como una posibilidad de consolidar las reglas de la BNCC, sino principalmente como una posibilidad que el Las prácticas pedagógicas pueden contribuir a la formación de seres humanos integrales capaces de actuar éticamente en nuestra sociedad.

Palabras clave: Pedagogía Waldorf; Base Curricular Nacional Común; Habilidades. 


\section{Introdução}

Muito se tem discutido sobre as dificuldades em se atingir uma educação integral e humanizada. Aponta-se, inclusive, para a carência dos modelos de educação atuais, que acabam por reduzir o aluno a um simples futuro candidato a um bom cargo de trabalho, enfocando somente no tão esperado sucesso profissional. Assim, o que se percebe é que muito pouco se vê avançar na busca por um novo modelo que possibilite a formação de sujeitos conscientes de seus potenciais e maduros, que tenham essa capacidade de transformar seus questionamentos em mudanças reais.

Acredita-se que uma pedagogia humanizada, adaptada à atualidade, precisa envolver o ser humano na totalidade de suas capacidades: corpo, mente, emoção e espírito. Considerando, assim, a totalidade e a liberdade como características essenciais para uma educação como um todo.

É nesta direção que se apresenta a pedagogia Waldorf, idealizada por Rudolf Steiner, como uma das mais diferenciadas correntes pedagógicas, pois seu aspecto principal é a concepção do homem e do mundo, a forma como o mesmo compreende e atua na realidade frente às necessidades de transformação. A prática educativa Waldorf fundamenta-se na visão do homem como uma unidade harmônica físico-anímico-espiritual, o que faz com que a Pedagogia Waldorf possua uma preocupação e uma visão de muito respeito para com o ser humano.

Pensando nisso, este artigo tem como objetivos principais trazer uma breve apresentação da Pedagogia Waldorf e discutir suas possibilidades na formação do ser-humano como um todo. Neste sentido, busca-se entender como a pedagogia Waldorf atua na formação educacional, relacionando-a com as competências apontadas pela Base Nacional Comum Curricular (BNCC) (Brasil, 2017). A BNCC é um conjunto de práticas que buscam articular as experiências e os saberes dos sujeitos com os conhecimentos que fazem parte do patrimônio cultural, artístico, ambiental, científico e tecnológico, de modo a promover o desenvolvimento integral das crianças e adolescentes em momento de construção de saberes.

Deste modo, realizou-se um estudo de cunho teórico buscando compreender como esta pedagogia coloca em prática o desenvolvimento das competências estabelecidas na Base Nacional Comum Curricular e se a pedagogia Waldorf consegue atender ao desenvolvimento do aluno considerando as competências estabelecidas pela Base.

Espera-se contribuir para um melhor entendimento desta pedagogia tão inovadora como a Waldorf e para o desenvolvimento da criança considerando os preceitos da Base 
Nacional Comum Curricular.

\section{Metodologia}

Para a construção deste estudo, foram adotados procedimentos metodológicos específicos para se obter resposta aos questionamentos propostos. Assim, foi empregado o método bibliográfico que, segundo Michel (2015), tem o objetivo de levantar informações a partir de leituras para que se possam definir os objetivos e problemas a serem resolvidos. A partir das leituras é que se pode entender, aprofundar-se sobre o assunto e descrevê-lo. "Esse tipo de pesquisa procura explicar um problema a partir de referências teóricas publicadas em documentos, dispensando a elaboração de hipóteses" (Michel, 2015, p. 48).

Assim, além de permitir o levantamento das pesquisas referentes ao tema estudado, a pesquisa bibliográfica permite ainda o aprofundamento teórico que norteia o tema a ser pesquisado. E, embora exista pouca bibliografia, as mesmas são de suma importância para a pedagogia Waldorf. Na consulta a base de dados Google acadêmico, não foram encontrados materiais que mencionassem as expressões BNCC e Pedagogia Waldorf nos últimos cinco anos. Deste modo, seguiu-se uma busca não-sistemática na internet que pudesse auxiliar na construção das reflexões deste estudo. Assim, foram utilizadas referências como os livros de Lanz $(2011 ; 2013)$ "Noções Básicas da Antroposofia” e "A Pedagogia Waldorf: caminho para um ensino mais humano", o site da Sociedade Antroposófica no Brasil e artigos como “BNCC e Educação Infantil: quais as possibilidades?" (Barbosa; Campos, 2015), “Auto educação e liberdade na Pedagogia Waldorf" (Junior; Stoltz; Veiga, 2013) e "Educação e ludicidade: um diálogo com a pedagogia Waldorf' (Silva, 2015), bem como a Base Nacional Comum Curricular da Educação Infantil (Brasil, 2017).

\section{Considerações Iniciais sobre a Pedagogia Waldorf}

Rudolf Steiner, criador da pedagogia Waldorf, era místico, filósofo, terapeuta, artista, cientista apreciador da natureza e doutor em filosofia (Lanz, 2011). Durante sua vida de estudos dedicou-se a Teosofia, expressão que tem origem da palavra grega Theosophia e significa primária e literalmente "Sabedoria Divina".

A Teosofia foi cunhada em Alexandria, no Egito, no século III d.C. por Amônio Saccas e seu discípulo Plotino que eram filósofos neo-platônicos. A Escola Teosófica Eclética 
era chamada de Philaletheus (Amantes da Verdade) e Analogistas, porque não buscavam a sabedoria apenas nos livros, mas através de analogias e correspondências da alma humana com o mundo externo e os fenômenos da Natureza.

Inspirado nesta ciência, Steiner criou a sociedade de Antroposofia, que vem do grego e significa "conhecimento do ser humano" (Lanz, 2011). Deste modo, a Antroposofia se caracteriza como um método de conhecimento da natureza do ser humano e do universo, que amplia o conhecimento obtido pelo método científico convencional, bem como a sua aplicação em praticamente todas as áreas da vida humana.

Foi ajudando trabalhadores com palestras, em princípios de 1919, em uma fábrica de cigarros, chamada de Waldorf/Astória em Stuttgart na Alemanha, que Rudolf Steiner ajudou os trabalhadores a conhecer melhor o propósito de seus trabalhos. Assim, conseguiu uma relação mais humana entre eles e para com o trabalho que os mesmos faziam, relacionando temas sociais e educativos. E assim, aos poucos, foi surgindo a pedagogia Waldorf.

A partir daí os trabalhadores desejaram implantar esta pedagogia na educação escolar de seus filhos, pois a sentiam mais adequada às necessidades reais do desenvolvimento humano na atualidade da época e, em 1919, foi criada a primeira escola Waldorf, sob orientação do próprio Steiner. Para eles, a pedagogia Waldorf se colocava como uma importante forma de educar seus filhos, uma vez que, nesta pedagogia, a criança é instigada desde cedo a entrar em contato com a natureza, desenvolver suas habilidades e também desenvolver-se integralmente como um ser humano livre e autônomo.

As instituições onde se emprega a Pedagogia Waldorf são conhecidas ou chamadas de escolas Waldorf e hoje já estão presentes nos cinco continentes. Com relação às escolas, Lanz (2013, p. 87) contribui dizendo que, "como organismos vivos, elas escapam a qualquer definição. [...] Sua razão de ser é a aplicação de um método pedagógico".

Lanz (2013) apresenta os aspectos principais e necessários para a existência de uma escola Waldorf: primeiro, a liberdade quanto às metas de educação, para ele, deve haver a possibilidade de conceber essas metas da forma mais ampla possível (Lanz, 2013). Além disso, a escola Waldorf quer ser algo mais do que as escolas tradicionais; se fosse incapacitada para desempenhar essas funções, não poderia existir o segundo aspecto fundamental: a liberdade quanto ao método pedagógico, que, para Lanz (2013), é a pedra de toque de sua existência, pois é principalmente por seu método pedagógico que ela se distingue das outras escolas. Esse método é sua razão de ser. Por fim, o último aspecto apontado pelo autor traz que: a liberdade quanto ao currículo. Embora tenha uma importância menor em 
comparação com o método, o currículo constitui uma das características fundamentais de uma escola Waldorf:

A liberdade quanto ao currículo não significa que matérias exigidas pelos programas oficiais de ensino não sejam aí ensinadas; significa, ao contrário, que matérias adicionais possam ser incluídas em seu programa, e sobretudo que cabe à escola determinar a época em que as matérias devem ser ensinadas” (Lanz, 2013, p. 183).

Percebe-se o quanto as escolas Waldorf pressupõem um regime de liberdade de ensino. A ponte entre a concepção filosófica da liberdade e sua presença no campo educativo Waldorf depende de um exercício ativo. Steiner fundamenta sua Filosofia da Liberdade nos conceitos de consciência intuitiva, fantasia e técnica moral. A consciência intuitiva é um nível mental acima da racionalidade, que capta a essência dos fenômenos sem ficar restrita aos limites da racionalidade. A fantasia moral é uma capacidade humana de criar representações que orientem o sujeito no seu campo de ação, de acordo com o contexto em que este vive. A consciência intuitiva abrange o universal enquanto a fantasia moral conecta a essência da ideia universal à particularidade do contexto. A técnica moral é o conjunto de conhecimentos em relação ao objeto de ação. Na educação, isto significa um verdadeiro conhecimento do ser humano.

Junior, Stoltz e Veiga (2013) colocam que o pensar intuitivo dos educadores pode ser compreendido como a ponte para a apreensão da ideia de educação, trazendo a necessidade de que o educador se comprometa com sua própria autoeducação. Os autores lembram ainda o quanto a ideia de educação não consiste somente em formar a capacidade de aprender, mas também a de se autorrealizar.

Como fonte de parâmetros, a ideia de educação precisa, sempre, ser reacessada, ela é o norte teórico. Para concretizá-la na realidade, os educadores têm o desafio de ativar sua fantasia moral, sua capacidade de criar representações adequadas ao seu mundo perceptual (contexto). Essas representações visam o direcionamento e a configuração da ação pedagógica, respeitando as leis do desenvolvimento do ser dos educandos (técnica moral). A autoeducação é considerada como o ativamento de um exercício pessoal para impulsionar a própria capacidade intuitiva e de fantasia do educador, ambas vinculadas com o conhecimento das leis que envolvem o amadurecimento humano. Exercício que pode ser incitado numa perspectiva intrapessoal, ou seja, do profissional que atua com sua individualidade e ideais dentro dessa proposta educativa. Mas o exercício também pode explorar a relação 
interpessoal, investigando como é exercida a ideia de liberdade nos encontros, nas relações sociais, principalmente entre docente e corpo discente.

Outro aspecto importante para compreender a proposta pedagógica de uma escola Waldorf é o brincar. Para esta proposta, o brincar é essencial para o desenvolvimento saudável da criança. O que se propõe é um ambiente que convide as crianças ao brincar livre, não estruturado, em que as próprias crianças possam inventar seus jogos e suas regras. Para Bogarin (2012, p. 75), “o brincar é apropriação ativa da realidade por meio da representação; a brincadeira é, por conseguinte, aprendizagem”. Sendo assim, o brincar não se resume à pura diversão, mas influencia diretamente no desenvolvimento contribuindo posteriormente inclusive pra vida acadêmica da criança.

Assim, na idade pré-escolar, a criança desenvolve-se em grande parte através do brincar. O brincar é tão importante e sério como o trabalho para o adulto. Ao brincar, a criança vai adquirindo experiências e vivências com as quais vai aprendendo a se situar em seu meio ambiente. É no brincar que a criança conhece o mundo e a si mesma e desenvolve capacidades de relacionamento social e coordenação motora. Considerando estes fatores, torna-se importante acrescentar que toda pedagogia Waldorf centra-se na ludicidade (Silva, 2015), sendo esta entendida como uma experiência de máxima integração entre seu pensar, seu sentir e seu fazer. Deste modo, a pedagogia Waldorf se coloca como:

uma educação que se propõe a transcender o ensino instrumental e conteudista, ou que, em outras palavras, pode ser considerada uma educação integral ou global, isto é, portanto, centrada na ludicidade, o que equivale a dizer que é uma educação lúdica (Silva, 2015, p. 112).

Compreende-se, por meio das considerações acima, que a Pedagogia Waldorf busca mobilizar a construção de um sujeito integral, capaz de colocar-se na sociedade como alguém livre e autônomo no que tange ao pensamento. Ao priorizar a liberdade do ensino e a arte de educar por meio de recursos como consciência intuitiva, fantasia, técnica moral e ludicidade, a Pedagogia Waldorf se torna capaz de suscitar o raciocínio, o equilíbrio emocional, a iniciativa e o compromisso social.

\section{Os Setênios na Formação do Ser-humano}

A filosofia Waldorf considera que o ser humano seja capaz de realizar conceitos, teorias e formas de se relacionar de forma única e pessoal, a partir das impressões que recebe, 
isto porque ao nascer o homem é portador de um potencial de predisposições e capacidades que ao longo de sua vida se desenvolvem. Os potenciais e predisposições segundo esta prática pedagógica fundamentam-se no desenvolvimento dos seres humanos segundo princípios gerais evolutivos que compreendem etapas de 7 a 7 anos, que são denominadas setênios.

Cada setênio apresenta momentos claramente diferenciáveis, nos quais surgem ou despertam interesses, perguntas latentes e necessidades concretas. Deste modo, para melhor compreensão, vamos apresentar brevemente cada um destes setênios, seguindo considerações principalmente de Lanz (2013):

$1^{\circ}$ Setênio: “O mundo é bom!": Neste período que vai do 0 a 7 anos a criança está aberta para o mundo, tem a confiança ilimitada, recebe impressões sensoriais e não elabora julgamentos ou análise. Está na fase do desenvolvimento motor, as percepções inadequadas são armazenadas no inconsciente, pois não compreende o pensamento dos adultos. Os educadores que optam por esta pedagogia neste período devem ser o exemplo de dignidade, pois a imitação faz parte do desenvolvimento infantil desta etapa.

Por estes motivos, neste primeiro setênio, o ambiente da sala de aula é muito importante e deve ser aconchegante, sendo sugerido o uso de mesas grandes para que as crianças tenham uma vivência do social nas refeições e algumas outras atividades. Além disso, a área externa de uma escola Waldorf também deve proporcionar vivencias com colegas e com a natureza. Há necessidade de espaço onde a criança possa desenvolver a motricidade. Nesta etapa, a criança brinca bastante e torna-se importante lembrar que a forma de brincar da criança é influenciada pela fantasia e pela imitação; ela imita o trabalho e os gestos dos adultos. E aqui os educadores têm que estar atentos aos seus gestos e posturas diante da criança.

Já no $2^{\circ}$ Setênio a frase-chave para sua compreensão é “O mundo é belo!": A criança um pouco maior, de 07 a 14 anos, começa a despertar para a maturidade sexual, ocorre o desenvolvimento anímico, há uma emancipação da vida corporal e há também uma interação e reação a estímulos que recebe. A criança neste período necessita de explicações conceituadas, há um interesse e admiração pelas coisas e as suas causas. Os sentimentos afloram e tomam conta dos sentidos da criança, ou seja, ela se torna mais emotiva.

A partir desta etapa, cada grupo de alunos que ingressa no primeiro ano terá um(a) professor(a) que acompanhará essa turma durante os oito anos do Ensino Fundamental. Além de ministrar as matérias básicas para as quais estiver apto, através da intensa convivência, o professor tem a possibilidade de conhecer em profundidade cada criança e pode desenvolver 
um acompanhamento mais individualizado e balizado nas necessidades de cada uma delas. $\mathrm{O}$ professor da classe acompanha o grupo em viagens de estudo, estabelece o elo entre as famílias das crianças e objetiva criar um grupo social integrado entre elas.

O $3^{\circ}$ Setênio vai dos 14 aos 21 anos de idade. Neste período os alunos já fazem um juízo próprio dos acontecimentos, que são os resultados das observações e vivências dos outros setênios. Nesta fase o professor atua com sua personalidade intelectual e moral, exigindo dos alunos capacidades e qualidades diferentes daquelas exigidas pelo professor do jardim da infância. Este torna-se mais um mentor, pois sua presença já não é tão necessária.

Conforme Lanz (2013), a relação professor-aluno é o cerne da Pedagogia Waldorf. O íntimo relacionamento entre professor e aluno é considerado um dos princípios básicos no seu currículo. Os professores precisam conhecer profundamente seus alunos para assim desenvolver seu aprendizado da melhor maneira possível. Segundo Lanz (2013, p. 80), "são os professores que representam a pedagogia, praticando-a, e cada professor Waldorf encontrase com seus alunos a partir desse conceito geral”.

No que se refere à relação entre professor-aluno, entende-se o quanto é essencial para a formação dos alunos e necessita ter como base o amor e, principalmente, o respeito mútuo entre os mesmos. Para a Pedagogia Waldorf, o verdadeiro educador é aquele que se propõe uma constante busca espiritual, pela autoeducação consciente. Para estimular o desenvolvimento de seres humanos em formação, precisa estar ele próprio, aberto a se transformar. É o que toda criança ou jovem espera de qualquer adulto (Federação das Escolas Waldorf no Brasil). O adolescente busca confirmar o que é realmente verdadeiro no ser humano, e precisa tornar sua mente aguçada. O professor, agora sim, já não deve ser aquela autoridade a quem se admira, mas um amigo com quem se questiona a vida (Lanz, 2013).

Nesta direção, o currículo Waldorf considera não só o gradual desenvolvimento das capacidades intelectuais, mas, igualmente, o desenvolvimento gradativo da alma infantil e de sua capacidade e interesse pelo fazer prático. O mundo é apresentado paulatinamente, desde o mundo mágico dos contos de fadas, passando pelo ritmo do tempo (dia e noite, estações do ano, etc.), entrando, as séries mais avançadas, na realidade histórica. O estudo das ciências também se descortina de forma gradual, abordando o homem e a natureza. Não é apenas através de uma observação objetiva exterior, mas procurando igualmente vislumbrar a realidade espiritual que tudo permeia. Deste modo, compreende-se que a Pedagogia Waldorf desenvolveu as épocas como forma de possibilitar aos alunos um maior aprofundamento dos grandes temas trazidos. 
Assim, como exemplo, é trabalhada uma época de História por 3 ou 4 semanas e a criança vivencia uma integração de matérias que gira em torno do tema abordado. Pode-se seguir uma época de Matemática ou de Português e, assim, sucessivamente, as épocas se desenrolam ao longo do ano. O ensino em épocas possibilita que os alunos recebam os conteúdos de uma forma não fragmentada, desconectada com o todo ou ainda de uma forma superficial. Além disso, as atividades artísticas desempenham um papel fundamental, estando presentes em todas as disciplinas. Assim também o fazer prático permeia todo o processo pedagógico contribuindo com o desenvolvimento de talentos e habilidades.

Como premissa para a pedagogia Waldorf, existe um programa específico de formação de professores, que os prepara e capacita para compreender o desenvolvimento da criança como um ser espiritual se encarnando num mundo terreno, bem como para que saibam de que forma propiciar o desabrochar de suas potencialidades nas épocas certas e da forma correta. Segundo o site da Federação das Escolas Waldorf no Brasil, os professores Waldorf são preparados para que se tornem, cada vez mais, capazes de perceber cada individualidade particular, cada criança como futuro adulto específico, com seus impulsos, perguntas e contribuições próprias.

Os professores de uma escola Waldorf devem ser personalidades amplamente interessadas pelo mundo atual, bem como profundos conhecedores da alma humana. $\mathrm{O}$ professor deve significar para cada criança a ponte entre esta criança e o mundo que a rodeia. Para isso é necessário que o professor seja um profundo conhecedor do mundo e da cultura de sua época, procurando compreender o que significam as diferentes correntes e movimentos culturais de seu tempo, conhecendo também a fundo as questões sociais, buscando expressálas e encontrar caminhos para elas.

\section{Pedagogia Waldorf e a BNCC}

A Base Nacional Comum Curricular (Brasil, 2017) é um documento normativo que visa nortear o ensino nas escolas de educação básica do Brasil. Neste documento é definido um conjunto de aprendizagens e competências que todos os alunos devem atingir durante a vivência do ensino básico, que compreende a Educação Infantil e também o Ensino Fundamental e Médio.

Deste modo, o documento da BNCC coloca-se como uma ferramenta orientadora para a elaboração do currículo específico de cada escola, sem desconsiderar as particularidades 
metodológicas, sociais e regionais de cada uma das regiões no Brasil. A BNCC fundamenta sua concepção pedagógica no desenvolvimento de competências, previsto na Lei de Diretrizes e Bases da Educação (LDB 9.394/96) (Brasil, 1996) e que são assim elucidadas:

Na BNCC, competência é definida como a mobilização de conhecimentos (conceitos e procedimentos), habilidades (práticas, cognitivas e socioemocionais), atitudes e valores para resolver demandas complexas da vida cotidiana, do pleno exercício da cidadania e do mundo do trabalho (Brasil, 2017, p. 8).

Deste modo, as competências são estabelecidas não só partindo daquilo que o estudante deve saber, mas principalmente o que deve saber fazer, estimulando desta forma o conhecimento, habilidades, valores e criticidade. Neste sentido ao adotar-se a Base Nacional Comum Curricular (BNCC) busca-se atender ao estabelecido no Plano Nacional de Educação (PNE) vigente, que tem como objetivo desenvolver a aprendizagem dos alunos, tanto da Educação Infantil, quanto do ensino fundamental e médio, para o desenvolvimento das competências sendo estas o principal objetivo.

Considera-se importante citar as dez competências gerais da educação básica, conforme a BNCC (Brasil, 2017):

1. Valorizar e utilizar os conhecimentos sobre o mundo físico, social, cultural e digital para entender e explicar a realidade, continuar aprendendo e colaborar com a sociedade.

2. Exercitar a curiosidade intelectual e utilizar as ciências, com criticidade e reflexão e criatividade, para investigar causas, elaborar e testar hipóteses, formular e resolver problemas e criar soluções.

3. Valorizar e fruir as diversas manifestações artísticas e culturais, para participar de práticas diversificadas da produção artístico-cultural.

4. Utilizar diferentes linguagens para se expressar e partilhar informações, experiências, ideias e sentimentos em diferentes contextos e produzir sentidos que levem ao entendimento mútuo.

5. Compreender, utilizar e criar tecnologias digitais de informação e comunicação de forma crítica, significativa, reflexiva e ética para se comunicar, acessar e disseminar informações, produzir conhecimentos e exercer protagonismo na vida pessoal e coletiva. 
6. Valorizar e apropriar-se de conhecimentos e experiências que possibilitem entender as relações próprias do mundo do trabalho e fazer escolhas alinhadas ao exercício da cidadania, com liberdade, autonomia, consciência crítica e responsabilidade.

7. Argumentar com base em fatos, dados e informações confiáveis, para formular, negociar e defender ideias, pontos de vista e decisões comuns que respeitem e promovam os direitos humanos e a consciência socioambiental, com posicionamento ético em relação ao cuidado de si mesmo, dos outros e do planeta.

8. Conhecer-se e compreender-se para cuidar da saúde física e emocional, reconhecendo suas emoções e as dos outros, com autocrítica e capacidade para lidar com elas.

9. Exercitar empatia, diálogo, resolução de conflitos e cooperação, para fazer-se respeitar e promover o respeito ao outro e aos direitos humanos, com acolhimento e valorização da diversidade humana, sem preconceitos de qualquer natureza.

10. Agir pessoal e coletivamente com autonomia, responsabilidade, flexibilidade, resiliência e determinação, para tomar decisões com base em princípios éticos, democráticos, inclusivos, sustentáveis e solidários.

Percebe-se que o conjunto das competências a ser desenvolvidas no campo educacional colocam como propósito último, que o/a estudante possa contribuir para a construção de uma sociedade mais justa, democrática, inclusiva, sustentável e cooperativa. $\mathrm{O}$ respeito aos direitos humanos, bem como à diversidade de vidas humanas colocam-se como competências fundamentais para a superação de preconceitos em nossa sociedade.

No que se refere ao campo da Educação Infantil, Barbosa e Campos (2015, p. 360) colocam que:

O documento da BNCC para a educação infantil é mais do que uma lista de atividades e/ou objetivos a serem cumpridos, antes é um documento que apresenta a defesa de uma determinada concepção de educação, de uma função da educação infantil e de qual deve ser o currículo privilegiado.

Assim, experiências como as emocionais, expressivas e de construção da individualidade devem ser incentivadas para que o sujeito criança se conheça melhor e construa sua identidade, individualidade, social e cultural, questionando e se utilizando de diferentes linguagens para agir eticamente na sociedade de modo amplo.

Percebe-se, assim, que a Pedagogia Waldorf atende inteiramente às normas da BNCC, ao se inserir em um contexto de compromisso com a educação integral voltada para a construção de uma sociedade mais justa, igualitária e colaborativa. Isso quer dizer que em 
seus fundamentos reconhece que a educação básica - em especial a Educação Infantil - deve trabalhar o desenvolvimento global da criança, sem privilegiar a dimensão intelectual em detrimento da dimensão afetiva ou vice e versa.

Observa-se o compromisso da pedagogia Waldorf com a construção de processos educativos que buscam promover aprendizagens que estejam de acordo com as necessidades e possibilidades de cada aluno, respeitando seus interesses e singularidades. Afinal, para esta pedagogia em questão, a criança é entendida como um ser complexo e agente ativo de sua aprendizagem e, esta, a como resultado de sua ação e interação com o mundo físico e social que a cerca. Além disso, essa pedagogia, ao lançar mão do ensino em épocas, contribui para a não fragmentação dos saberes e para o olhar ampliado dos estudantes para todas as dimensões da realidade, buscando com se tornem agentes de reconhecimento de suas emoções e do outro em sua diversidade.

Cabe acrescentar que os direitos de aprendizagem e desenvolvimento surgem na BNCC para assegurar situações de aprendizagem em que as crianças desempenhem papeis ativos na construção de significados acerca do mundo, sobre si e os outros. Neste contexto é indispensável que as práticas pedagógicas na Educação Infantil sejam marcadas por uma intencionalidade educativa. Isso quer dizer que cabe ao educador "[...] refletir, selecionar, organizar, planejar, mediar e monitorar o conjunto das práticas e interações, garantindo a pluralidade de situações que promovam o desenvolvimento pleno das crianças" (Brasil, 2017, p. 37). Nesta direção, a proposta Waldorf traduz sua intencionalidade educativa a partir de cada direito de aprendizagem e desenvolvimento da criança através do brincar. Neste sentido, a BNCC, para a Educação Infantil, também descreve que a criança brinque aprendendo. É notório que a pedagogia Waldorf e a BNCC colocam intencionalidades educativas distintas, mas ambas têm relações importantes que estabelecem o direito da criança ao desenvolvimento brincando e experimentando. Estes direitos como brincar, conviver, participar, explorar, expressar-se e conhecer, torna o desenvolvimento da criança mais completo e mais autônomo, segundo as duas concepções aqui já citadas para que estas crianças se tornem seres humanos mais completos e intuitivos.

Percebe-se, segundo a intencionalidade educativa da pedagogia Waldorf, que no primeiro setênio (de zero aos sete anos), que corresponde à Educação Infantil, a criança desenvolve uma grande abertura em relação ao mundo, com confiança ilimitada. Nesse sentido, essa intencionalidade procura ampliar, cada vez mais, através de uma forma livre, o conviver, já que a criança se encontra em um meio social, participando assim de atividades 
em grupos e tendo oportunidades de explorar o mundo ao se redor, o que traduz um dos preceitos importantes da BNCC. Além disso, a Base, no que tange à Educação Infantil, também coloca a urgência de construção e desenvolvimento de uma educação mais intuitiva, que busque os preceitos de liberdade, pensamento intuitivo e a globalidade do ser humano.

É neste processo intuitivo, livre e lúdico do aprender brincando que a pedagogia Waldorf transcende a mera transmissão de conhecimentos e se converte em sustentação do desenvolvimento integral do educando, cuidando que tudo o que se faça tenha como meta a transformação de sua vontade e o cultivo de sua sensibilidade e intelecto.

Desse modo, a pedagogia Waldorf, atendendo às inspirações da Base, procura estabelecer uma relação harmônica entre desenvolvimento e aprendizagem, fazendo confluir a dinâmica interna da pessoa com a ação pedagógica direta, ou seja, fazendo integrar os processos de desenvolvimento individual com a aprendizagem da experiência humana culturalmente organizada.

Neste processo de desenvolver o conhecimento, sem que se torne algo pesado e cansativo, a pedagogia Waldorf vem ao encontro da BNCC, pois a primeira trata do aprendizado através do brincar, do expressar-se para desenvolver-se individualmente e integralmente tanto na experiência humana quanto na aprendizagem, voltando-se para a troca respeitosa em uma sociedade que, espera-se, se torne mais justa, democrática e ética.

\section{Considerações Finais}

Por meio deste estudo, percebeu-se que, no campo educacional, há uma importante discussão em torno das possibilidades de desenvolvimento integral do ser humano. Desta forma, a pedagogia Waldorf desenvolvida por Rudolf Steiner vem se colocando como um importante arcabouço de compreensão do ser humano que parece ampliar a visão para uma proposta pedagógica bastante singular e integradora. Steiner elaborou não somente uma concepção do ser humano, mas também uma grandiosa concepção da vida, tudo isso através da Antroposofia que vem inspirando a pedagogia e muitas outras áreas do saber.

Levando em consideração o desenvolvimento integral do ser humano, sobretudo na infância, a proposta pedagógica da BNCC e do artigo 29 da LDB (1996), ressaltam o indivíduo em sua integralidade. Desta forma, colocam que a finalidade da Educação Infantil seja "o desenvolvimento integral da criança até 6 anos de idade em seus aspectos físico, psicológico, intelectual e social, complementando a ação da família e da comunidade" (Brasil, 
1996). Assim sendo, percebeu-se que tanto as diretrizes da BNCC, quanto a Pedagogia Waldorf, estabelecem relações a partir da ideia de indissociabilidade entre o cuidado e a educação no atendimento às crianças, na construção de um vínculo entre quem cuida e quem é cuidado, estabelecendo relações e propostas para estas necessidades da educação infantil.

Percebeu-se, por meio deste estudo, que a pedagogia Waldorf pode ser entendida como uma alternativa de concretização dos preceitos da $\mathrm{BNCC}$, tendo em vista que ambas esforçam-se por fomentar um ser humano ético, livre, crítico, autônomo, que possa agir na sociedade com compromisso, respeito a si e aos outros, com dialogo, responsabilidade, empatia, cooperação e possa, assim, ser, desde a educação infantil, um agente de construção e fortalecimento da cidadania e do respeito a diversidade social e cultural em nosso país.

Por fim, espera-se que este estudo possa contribuir para o campo educacional, tendo em vista que o foco deste, a pedagogia Waldorf, apresentou-se não apenas como uma possibilidade de consolidação das normativas da $\mathrm{BNCC}$, mas principalmente como possibilidade de que a práticas pedagógicas possam contribuir para a formação de seres humanos integrais aptos a atuarem eticamente em nossa sociedade.

\section{Referências}

Barbosa, M. C. S. \& Campos, R. (2015). BNCC e Educação Infantil: quais as possibilidades? Retratos da Escola, Brasília, 9(17), 353-66.

Bogarin, M. C. S. P. B. (2012). A qualidade da educação infantil no contexto da Pedagogia Waldorf: um estudo de caso. Dissertação (Mestrado em Educação) - Faculdade de Educação, Universidade de Brasília. Brasília Brasil. 157 p

Brasil. (1996). Lei de Diretrizes e Bases da Educação Nacional. Lei no. 9394. Diário Oficial da União. Brasília, DF: Senado Federal, Coordenação de Edições Técnicas. Recuperado de https://www2.senado.leg.br/bdsf/bitstream/handle/id/529732/lei_de_diretrizes_e_bases_1ed.p df.

Brasil. (2017). Ministério da Educação. Base Nacional Comum Curricular. Brasília, DF: Ministério da Educação. Recuperado de http://basenacionalcomum.mec.gov.br/images/BN CC_EI_EF_110518_versaofinal_site.pdf. 
Federação das Escolas Waldorf no Brasil. Recuperado de http://www.fewb.org.br .

Júnior, J. B., Stoltz, T., Veiga, M. (2013). Autoeducação e liberdade na Pedagogia Waldorf. Educação: Teoria e Prática. 23 (42), 161-175.

Lanz, R. (2011). Noções Básicas da Antroposofia. São Paulo: Antroposófica.

Lanz, R. (2013). A Pedagogia Waldorf: caminho para um ensino mais humano. (11a ed.), São Paulo: Antroposófica.

Michel, M. H. (2015). Metodologia e pesquisa em ciências sociais: um guia prático para acompanhamento da disciplina e elaboração de trabalhos monográficos. (3a ed.) São Paulo: Atlas.

Pereira, A. S. et al. (2018). Metodologia da pesquisa científica. [e-book]. Santa Maria. Ed. UAB/NTE/UFSM. Recuperado de https://repositorio.ufsm.br/bitstream/handle/1 /15824/Lic_Computacao_Metodologia-Pesquisa-Cientifica.pdf?sequence=1.

Silva, D. A. A. (2015). Educação e ludicidade: um diálogo com a pedagogia Waldorf. Educar em Revista, s/vol (56), 101-113.

Sociedade Antroposófica no Brasil. Recuperado de http://www.sab.org.br/portal/

\section{Porcentagem de contribuição de cada autor no manuscrito}

Gabriela Luz Saraiva - 50\%

Marcele Pereira da Rosa Zucolotto - 50\% 